\title{
Makna Pemeringkatan dan Peningkatan Kinerja Perguruan Tinggi Perspektif Intellectual Capital
}

\author{
Sigit Hermawan ${ }^{1}$ \\ Sriyono ${ }^{2}$ \\ Wiwit Hariyanto 3 \\ Niko Fediyanto ${ }^{4}$ \\ ${ }^{1,2,3,4}$ Fakultas Ekonomi dan Bisnis, Universitas Muhammadiyah Sidoarjo, Indonesia \\ email : sigithermawan@umsida.ac.id
}

DOI: https://doi.org/10.24843/JIAB.2019.v14.i02.p01

\section{Jurnal Ilmiah Akuntansi dan Bisnis (JIAB)}

https://ojs.unud.ac.id/index.php/jiab/ user/profile

Volume 14

Nomor 2

Juli 2019

Halaman 142-154

p-ISSN $\underline{2302-514 X}$

e-ISSN 2303-1018

\section{INFORMASI ARTIKEL}

Tanggal masuk: 05 Pebruari 2019

Tanggal revisi:

06 Mei 2019

Tanggal terima:

24 Juni 2019

\begin{abstract}
ABSTRAK
Tujuan penelitian adalah untuk menganalisis makna pemeringkatan dan merumuskan upaya meningkatkan kinerja dan daya saing perguruan tinggi dari perspektif intellectual capital. Jenis penelitian adalah kualitatif interpretif. Pengumpulan data dilakukan dengan in depth interview, focus group discussion $(F G D)$, observasi, dan pendokumentasian. Analisis data dilakukan selama proses penelitian dengan empat tahapan, yakni data collection, data reduction, data display, dan conclusion. Hasil penelitian menyatakan makna pemeringkatan adalah terkait dengan kinerja, media promosi, dan terkait dengan reputasi atau image building. Untuk upaya meningkatkan kinerja dan daya saing perguruan tinggi dapat dilakukan dengan mengoptimalkan peran human capital, structural capital, dan relational capital baik secara individual ataupun secara teintegrasi sebagai intellectual capital. Cara lain yang dapat digunakan adalah dengan metode comprehensive intellectual capital management atau CICM.
\end{abstract}

Kata kunci: Pemeringkatan, kinerja, daya saing, intellectual capital

The Meaning of Ranking and University Performance Improvement Based on Intellectual Capital Perspective

\section{ABSTRACT}

The purpose of this research is to analyze the meaning of ratings and formulate efforts to improve the performance and competitiveness of universities in the intellectual capital perspective. The interpretive qualitative research type was used. Data collection was carried out using in-depth interviews, focus group discussions, observations, and documentation. Data analysis was carried out throughout the four-stage research process involving data collection, data reduction, data display, and conclusion. The results of the study state that the meaning of ratings is related to performance, media promotion, and related to reputation or image building. Efforts to improve the performance and competitiveness of universities can be done by optimizing the role of human capital, structural capital, and relational capital both individually and integrated as intellectual capital. Another method that can be used is the comprehensive intellectual capital management or CICM method.

Keywords: Ranking, performance, competitiveness, intellectual capital

\section{PENDAHULUAN}

Pemeringkatan perguruan tinggi merupakan pemberian peringkat atau urut-urutan berdasarkan kriteria tertentu pada perguruan tinggi. Pemeringkatan perguruan tinggi dapat dilakukan oleh lembaga pemerintah, swasta, dalam, ataupun luar negeri. Misalnya pemeringkatan perguruan tinggi oleh Kopertis Wilayah VII Jawa Timur atau LLDIKTI 7 
Jawa Timur, DIKTI, Webometrics, atau 4 Internal Colleges \& Universities (4ICU). Tujuan sistem ranking atau pemeringkatan webometrics adalah untuk menyediakan informasi yang handal, akurat, multi dimensi, dan berguna kepada masyakarat tentang kinerja perguruan tinggi di seluruh dunia berdasarkan kehadiran dan dampaknya di dunia maya (internet space). Sistem ini dimulai tahun 2014 yang selanjutnya setiap 6 (enam) bulan sekali dikeluarkan sistem informasi rangking terkini. Sementara itu tujuan pemeringkatan atau klasterisasi oleh DIKTI adalah untuk capaian kinerja perguruan tinggi di Indonesia sehingga akan lebih memudahkan dalam hal kebijakan apabila sudah ada klasterisasi sesuai perguruan tinggi yang ada. (http://kelembagaan.ristekdikti.go.id).

Pemeringkatan terkandung makna tentang kinerja dan daya saing perguruan tinggi. Misalnya pemeringkatan yang dilakukan oleh webometrics yang juga pemeringkatannya dapat didasarkan per negara, per wilayah, dan juga sedunia. Demikian juga pemeringkatan versi 4ICU. Kinerja dan daya saing menjadi kata yang mendasar dari usaha pemeringkatan tersebut. Pada Tabel 1. disajikan data pemeringkatan yang dilakukan oleh lembaga pemeringkatan dunia untuk perguruan tinggi di Indonesia.

\section{Tabel 1. Pemeringkatan Perguruan Tinggi oleh Lembaga Internasional}

\begin{tabular}{lll}
\hline \multicolumn{1}{c}{ Webometrics } & \multicolumn{1}{c}{ 4ICU } & QS World University Ranking \\
\hline Univ Gadjah Mada & Univ Gadjah Mada & Univ Indonesia \\
Univ Indonesia & UNIBRAW Malang & ITB Bandung \\
ITB Bandung & Univ Indonesia & Univ Gadjah Mada \\
IPB Bogor & Univ. Negeri Yogyakarta & IPB Bogor \\
UNDIP Semarang & UNDIP Semarang & Unair Surabaya \\
UNIBRAW Malang & Univ Negeri Sebelas Maret Surakarta & UNPAD Bandung \\
ITS Surabaya & IPB Bogor & ITS Surabaya \\
UNS Surakarta & UNAIR Surabaya & Univ BINUS Jakarta \\
Univ Syah Kuala & Univ Lampung & UNDIP Semarang \\
UNPAD Bandung & Univ Muhammadiyah Surakarta & UNIBRAW Malang \\
\hline
\end{tabular}

Sumber: Data Diolah, 2019.

Hasil pemeringkatan perguruan tinggi non vokasi juga disampaikan oleh Kemenristek DIKTI untuk tahun 2018. Pada Tabel 2. disajikan data pemeringkatan perguruan tinggi non vokasi yang masuk dalam klaster 1, yakni:

Tabel 2. Pemeringkatan Perguruan Tinggi Non Vokasi oleh Kemenristek DIKTI

\begin{tabular}{lc}
\hline \multicolumn{1}{c}{ Webometrics } & Skor Total \\
\hline Institut Teknologi Bandung & 3,57 \\
Universitas Gadjah Mada & 3,54 \\
Institut Pertanian Bogor & 3,41 \\
Universitas Indonesia & 3,28 \\
Universitas Diponegoro & 3,12 \\
Institut Teknologi Sepuluh Nopmeber & 3,10 \\
Universitas Airlangga & 3,03 \\
Universitas Hasanudih & 2,99 \\
Universitas Padjajaran & 2,95 \\
Universitas Andalas & 2,88 \\
Universitas Negeri Yogyakarta & 2,83 \\
Universitas Brawijaya & 2,82 \\
Universitas Pendidikan Indonesia & 2,70 \\
Universitas Negeri Malang & 2,16 \\
\hline
\end{tabular}

Sumber: https://ristekdikti.go.id, 2018

Pemeringkatan yang dilakukan oleh Kemenristek DIKTI tersebut didasarkan pada lima komponen utama, yakni 1) kualitas SDM; 2) kualitas kelembagaan;
3) kualitas kegiatan kemahasiswaan; 4) kualitas penelitian dan pengabdian pada masyarakat; 5) kualitas inovasi. 
Sementara itu kinerja universitas yang ada di Indonesia jauh tertinggal dengan universitasuniversitas yang ada di Asia Tenggara, seperti universitas di Malaysia, Thailand dan Singapura. Menurut data Webometrics Januari 2019, tercatat Universitas Gadjah Mada (UGM) adalah perguruan tinggi peringkat pertama di Indonesia. Apabila dibandingkan dengan universitas peringkat pertama di Malaysia, yakni University of Malaya, jarak peringkatnya sangat jauh. Peringkat UGM di tingkat Asia adalah 176 sedangkan University of Malaya ada di peringkat 57. Selanjutnya di tingkat dunia, UGM berada di peringkat 843 sedangkan University of Malaya di peringkat 374 (Webometrics, Januari 2019), Berikut data pemeringkatan universitas terbaik di empat negara (Singapura, Malaysia, Thailand, dan Indonesia versi webometrics Januari 2019.

Tabel 3. Perbandingan Peringkat Universitas Terbaik di Empat Negara

\begin{tabular}{llcc}
\hline \multicolumn{1}{c}{ Negara } & \multicolumn{1}{c}{ Perguruan Tinggi } & Word Rank & Asia Rank \\
\hline Singapura & National University of Singapore & 57 & 4 \\
Malaysia & Universiti of Malaya & 374 & 57 \\
Thailand & Chulalangkorn University & 490 & 82 \\
Indonesia & Univesitas Gadjah Mada & 843 & 176 \\
\hline
\end{tabular}

Sumber: www.webometrics.info (Up date : Januari 2019)

Berdasarkan Tabel 3. diketahui bahwa peringkat kampus terbaik di Indonesia, yakni Universitas Gadjah Mada masih jauh tertinggal dibandingkan dengan tiga kampus terbaik di negara Singapura, Malaysia, dan Thailand. Tentang belum dapat bersaingnya perguruan tinggi Indonesia di Asia Tenggara juga dijelaskan oleh Syaifudin (2016) yakni:

"Jangankan di tingkat dunia, untuk bersaing dengan universitas negeri di Malaysia pun kini PTN unggulan kita masih kalah jauh baik dari aspek reputasi dosen, karya ilmiah (artikel di jurnal internasional dan paten), serta internasionalisasi".

Sementara itu terkait tentang kinerja dan daya saing, perspektif yang dapat dijadikan sebagai rujukan untuk peningkatan adalah intellectual capital. Intellectual capital adalah aktiva strategi yang sangat potensial dikaitkan dengan firm performance (Belkaoui, 2003). Berbagai penelitian yang dilakukan oleh Hayat et al. (2019), Sriwahyuni et al. (2019), Hermawan dan Mardiyanti (2016), Hermawan (2015), Hermawan dan Herlina (2013), Khalique et al. (2011), Sharabathi et al. (2010) menyatakan bahwa intellectual capital berpengaruh terhadap kinerja dan daya saing. Demikian juga pernyataan dari Popescu (2019) tentang peran intellectual capital dalam banyak hal di organisasi. Peran intellectual capital sebagai nilai instrinsik organisasi, sebagai penguat ekonomi dan keuangan organisasi, kekuatan organisasi secara menyeluruh, sebagai aset potensial masa mendatang yang dapat diandalkan menghadapi permintaan pasar, dan sebagai perspektif baru di masyarakat berbasis pendekatan ilmu pengetahuan. Intellectual capital dengan tiga komponennya, yakni human capital, structural capital, dan relational capital (Bontis et al., 2000) terbukti berpengaruh baik secara individual maupun terintegrasi terhadap kinerja perusahaan (Hermawan et al., 2012).

Selanjutnya metode pengelolaan intellectual capital juga dapat dijadikan sebagai rujukan untuk meningkatkan kinerja keuangan dan daya saing. Metode tersebut adalah comprehensive intellectual capital management (CICM) (Al-Ali, 2003). Penelitian Hermawan (2015) mendukung teori tersebut bahwa CICM dapat meningkatkan kinerja perusahaan. CICM memiliki tiga tahapan, yakni knowledge management (KM), innovation management (IM), dan intellectual property management (IPM). Hal ini juga sesuai dengan hasil penelitian Barbosa et al, (2016) yang menyatakan bahwa IC management dan pengukuran dapat menjadi bagian penting untuk meraih keunggulan bersaing bagi organisasi pendidikan tinggi di Portugis. Karena manajer perguruan tinggi dapat meningkatkan kinerja organisasi dan maksimalisasi efisiensi.

Terkait dengan teori dasar yang sesuai untuk pemeringkatan perguruan tinggi dan peningkatan kinerja dan daya saing berbasis IC adalah teori referensial dan teori sumber daya atau the resource based theory (Wernerfelt, 1984; Barney, 1991). Teori referensial digunakan untuk memaknai pemeringkatan perguruan tinggi dan the resource based theory untuk peningkatan kinerja dan daya saing berbasis $I C$. Teori referensial menyatakan 
bahwa makna sebuah barang atau benda tergantung pada gambaran seperti apa barang atau benda tersebut. Sedangkan teori sumber daya atau the resource based theory menyatakan bahwa asset perusahaan baik asset berwujud dan asset tak berwujud dapat menjadi asset strategis yang dikembangkan menjadi sumber daya yang meningkatkan kinerja dan daya saing perusahaan atau organisasi.

Penelitian tentang intellectual capital telah dilakukan oleh banyak peneliti di berbagai organisasi utamanya di organisasi profit oriented. Namun penelitian intellectual capital yang dilakukan di organisasi non profit oriented utamanya di universitas terkait dengan makna pemeringkatan dan peningkatan kinerja masih jangan dilakukan. Dengan demikian penelitian ini berbeda dengan penelitian intellectual capital yang lainnya.

Penelitian ini berbeda dengan penelitian Hermawan dan Milanetty (2018) yang meneliti intellectual capital disclosure pada perusahaan farmasi di Asia Tenggara. Penelitian ini juga berbeda dengan penelitian Hermawan dan Mardiyanti (2016) yang menguji pengaruh intellectual capital terhadap kinerja keuangan perusahaan high IC intensive. Demikian juga dengan penelitian Hermawan (2015) yang mengeksplore intellectual capital melalui CICM. Penelitian ini juga berbeda dengan penelitian Hermawan (2013) yang menganalisis makna intellectual capital perspektif the role theory dan the resources based theory. Adapun tujuan penelitian ini adalah untuk menganalisis makna pemeringkatan dan merumuskan upaya meningkatkan kinerja dan daya saing perguruan tinggi perspektif intellectual capital.

\section{METODE PENELITIAN}

Penelitian ini menggunakan pendekatan kualitatif interpretif. Hal tersebut dikarenakan penelitian ini bertujuan memahami makna dan data-data kualitatif yang diungkap oleh informan. Penelitian ini juga tidak menguji hipotesis dan tidak menghubungkan antar variabel (Hermawan dan Amirullah, 2016). Alasan lain menggunakan kualitatif interpretif karena penelitian ini banyak mengungkapkan fakta, fenomena, dan menginterpretasikan makna (Strauss dan Corbin, 2003) pemeringkatan, kinerja, dan daya saing perguruan tinggi Indonesia perspektif intellectual capital. Penelitian tentang makna perspektif intellectual capital pernah juga dilakukan oleh Hermawan (2016) dengan pendekatan kualitatif interpretif.
Fokus penelitian ini adalah mengungkapkan makna pemeringkatan, kinerja, dan daya perguruan tinggi Indonesia perspektif IC. Makna pemeringkatan yang dimaksud adalah pemeringkatan yang dilakukan oleh lembaga pemeringkatan dunia seperti webometrics dan lainnya. Arti penting pemeringkatan bagi perguruan tinggi, respon pimpinan perguruan tinggi atas hasil pemeringkatan, dan juga langkahlangkah dalam memperbaiki peringkat perguruan tinggi. Sementara itu, kinerja dan daya saing perguruan tinggi Indonesia yang dimaksud adalah hasil kerja dan daya saing perguruan tinggi Indonesia yang ditandai dengan hasil pemeringkatan oleh Kemenristek DIKTI atau juga lembaga pemeringkatan internasional. Perspektif $I C$ yang dimaksud adalah pengelolaan kinerja perguruan tinggi ditinjau dari perspektif human capital (HC), structural capital $(S C)$, dan relational capital $(R C)$.

Pendapat informan tentang makna pemeringkatan, kinerja, dan daya saing perguruan tinggi Indonesia berdasarkan perspektif intellectual capital dijadikan unit analisis dalam penelitian ini (Basuki, 2011). Hal tersebut dikarenakan pendapat informanlah yang dijadikan sebagai unit analisis karena memang itu yang diteliti, yakni kata-kata yang diungkapkan oleh informan tentang suatu fenomena penelitian.

Informan penelitian ini adalah pimpinan universitas yang diwakili oleh wakil rektor, pimpinan level menengah universitas yang diwakili oleh Dekan, Kepala Badan Penjaminan Mutu, dan dosen lain yang dipilih dengan judgment peneliti. penelitian ini disajikan dalam data informan pada Tabel 4.

Berdasarkan Tabel 4, dapat diketahui bahwa penelitian ini dilakukan dengan in depth interview dan $F G D$ untuk mendapatkan data penelitian, yakni pendapat informan tentang makna pemeringkatan, kinerja, dan daya saing perguruan tinggi Indonesia. Teknik pengumpulan data yang lain adalah dokumentasi dan observasi. Dengan demikian teknik pengumpulan data yang dilakukan dalam penelitian ini adalah in depth interview, focus group discussion $(F G D)$, pendokumentasian, dan observasi (Hermawan dan Amirullah, 2016).

Data penelitian ini diuji dengan uji credibility dan uji transferability (Senton, 2004; Hermawan dan Amirullah, 2016). Uji credibility dilakukan dengan triangulasi metode, triangulasi sumber, dan triangulasi teori. Uji tringulasi metode dan sumber dilakukan dengan cross check antara hasil metode wawancara in depth interview dengan $F G D$ ataupun juga dengan data dokumentasi. Misalnya hasil in depth 
Tabel 4. Informan Penelitian

\begin{tabular}{lll}
\hline \multicolumn{1}{c}{ Nama Informan } & \multicolumn{1}{c}{ Jabatan / Unsur } & \multicolumn{1}{c}{ Waktu Wawancara } \\
\hline Dr. UL, M.Si & Wakil Rektor II Universitas PGRI Adi & Indepth Interview tanggal 9 Juli 2018 \\
& Buana Surabaya & \\
Dr. AM, M.Si., Ak & Dekan FEB UMS & Indepth Interview tanggal 17 Juli 2018 \\
HCW, ST, MT & Kepala BPM Umsida / Kepala Tim & Indepth Interview tanggal 17 Juli 2018 \\
& Tata Kelola & Focus Group Discussion (FGD) tanggal \\
Dr. AR, MM & Dosen dan Ahli Marketing & 20 Juli 2018 \\
IDR, SE., M.Ak & Dosen dan Kepala BAK Umsida & \\
HF, SE., M.Si & Dosen dan Tenaga Ahli Kinerja & \\
REF, SE., M.SM & Dosen dan Tenaga Ahli MSDM & \\
SMT, SE., MM & Dosen dan Tenaga Ahli Marketing & \\
SB, SE., M.SA & Dosen dan Tenaga Ahli Daya Saing & \\
& & \\
\hline
\end{tabular}

Sumber: Data Diolah, 2019

interview dengan informan UL dikonfirmasi kepada informan HCW. Atau hasil in depth interview dengan informan HCW dikonfirmasi pada saat FGD dengan informan IDR. Konfirmasi juga dilakukan yakni hasil FGD dengan data dokumentasi tentang hasil pemeringkatan perguruan tinggi berdasarkan data webometrics. Untuk uji triangulasi teori dilakukan dengan konfirmasi hasil penelitian ini dengan teori yang digunakan, yakni the resource based theory. Untuk uji transferability dilakukan dengan membuat laporan penelitian yang lengkap, mudah dipahami, jelas, terinci, sistematis sehingga pembaca atau peneliti lain mudah memahami dan dapat mentransfer ke dalam penelitian yang akan dilakukan. Hal tersebut dikarenakan nilai transfer penelitian kualitatif tergantung pada pembaca sejauh mana dapat memahami laporan penelitian yang ada.

Untuk analisis data dilakukan selama proses pengumpulan data sebagaimana kekhasan penelitian kualitatif (Hermawan dan Amirullah, 2016). Adapun tahapan analisisnya mengikuti rekomendasi Miles dan Huberman (1984) adalah data collection, data reduction, data display, dan conclusion (Hermawan dan Amirullah, 2016). Data collection dilakukan atas semua teknik pengumpulan data baik in depth interview, FGD, data dokumentasi, dan observasi. Semua data dikumpulkan pada tahapan ini. Pada tahapan pengumpulan data ini peneliti melakukan proses analisis data dengan melihat kesesuaian antara hasil in depth interview, $F G D$, dokumentasi, dan observasi dengan panduan wawancara, rumusan masalah, teori yang digunakan, dan hasil penelitian terdahulu. Data reduction dilakukan dengan menyeleksi hasil dari data collection. Proses ini dilakukan selama pengumpulan data berlangsung. Peneliti melakukannya dengan memilih dan memilah data, apakah sesuai dengan tujuan penelitian, tema dan topik penelitian. Data akan dibuang apabila tidak sesuai dengan tema penelitian. Dengan demikian akan terkumpul tema atau konsep yang sama dan akan diberi kode (proses coding). Pada proses ini peneliti dapat mengetahui apakah data sudah cukup atau belum. Jika dirasa data belum cukup, peneliti dapat kembali mengambil data yang diperlukan dengan menghubungi informan yang dibutuhkan.

Berikutnya setelah data reduction adalah data display. Data display disusun dengan cara mendisplay atau memajang daftar wawancara ke dalam matriks display hasil penelitian. Dengan adanya matriks tersebut peneliti lebih mudah dalam memahami makna dari informan dan menempatkannya ke dalam laporan hasil penelitian. Dengan cara yang seperti itu menunjukkan kealamiahan penelitian kualitatif dan matriks tersebut ada di lampiran penelitian.

Tahap terakhir untuk analisis data adalah menyimpulkan atau conclusion. Pada tahapan ini peneliti menyimpulkan hasil penelitian. Kesimpulan pada penelitian kualitatif, awalnya belum pasti, masih ragu-ragu. Namun peneliti dapat kembali ke lapangan penelitian kalau dirasa belum cukup datanya. Seiring dengan bertambahnya data maka kesimpulan penelitian dapat diambil karena sudah lengkap dan jelas.

\section{HASIL DAN PEMBAHASAN}

Hasil penelitian didasarkan penggabungan antara pengumpulan data dan analisis data. Pada saat pengumpulan data sekaligus dilakukan triangulasi data, data reduction, dan coding. Proses tersebut didukung oleh kemampuan peneliti kualitatif sebagai instrument penelitian yang dapat menyeleksi datadata yang sama menjadi tema atau konsep yang sama tentang makna pemeringkatan dan peningkatan kinerja perguruan tinggi perspektif intellectual 
Tabel 5. Konsep Atau Pola Yang Sama Hasil Dari Proses Coding

\begin{tabular}{ll}
\hline Coding & \multicolumn{1}{c}{ Tema atau Konsep } \\
\hline \multirow{2}{*}{ A } & \multicolumn{1}{c}{ Tema atau Konsep Utama } \\
& Makna Pemeringkatan Bagi Perguruan Tinggi \\
& A.2. Respon Pemimpin atas Hasil Pemeringkatan \\
B & Upaya Meningkatkan Kinerja dan Daya Saing Perguruan Tinggi Perspektif Intellectual Capital \\
& B.1. Hasil Kinerja dan Daya Saing Perguruan Tinggi Indonesia \\
& B.2. Upaya Meningkatkan Kinerja dan Daya Saing Perguruan Tinggi Indonesia dari Perspektif Intellectual \\
& Capital
\end{tabular}

Sumber: Data Display Hasil Coding dan Data Reduction

capital. Tabel 5 menyajikan konsep atau tema yang sama hasil penelitian.

Berdasarkan proses coding dan data reduction, pendapat informan tentang makna pemeringkatan perguruan tinggi dapat terbagi menjadi dua bagian, yakni 1) arti penting pemeringkatan; dan 2) respon pimpinan perguruan tinggi atas hasil pemeringkatan sebagaimana Tabel 5. Adanya simpulan tentang makna pemeringkatan dan peningkatan kinerja perguruan tinggi perspektif intellectual capital didasarkan pada proses pengumpulan data, pemaknaan data atau interpretasi, dan analisis data dikaitkan dengan teoi pendukung, yakni teori referensial. Menurut Alston, teori referensial merupakan teori makna yang mengenali atau mengidentifikasi makna suatu ungkapan dengan apa yang diacunya atau dengan hubungan acuan itu. Artinya memang apa yang diungkapkan oleh informan dalam penelitian itu adalah mengacu pada hal yang penting sesuai dengan bahan yang diacu. Pada penelitian ini, informan menyatakan bahwa pemeringkatan itu penting bagi pimpinan perguruan tinggi sebagai acuan kinerja. Seperti yang disampaikan oleh informan Bapak UL, wakil rektor II Unipa Surabaya ketika diminta memberi tanggapan tentang banyaknya hasil pemeringkatan perguruan tinggi baik oleh KOPERTIS WILAYAH VII, DIKTI, atau berdasarkan webometrics.

"Selalu merespon positif dan menyiapkan semua komponen untuk ikut didalamnya. Tahun lalu kita di peringkat 8 dan tahun ini masih tetap di 10 besar. Intinya semua komponen dalam kampus ikut tergerak dan dilibatkan, mulai dari rektorat hingga ke tingkat lebih bawah. Karena komponen tata kelola kan sampai ke tingkat bawah. Hal ini karena dianggap bahwa nilai dari suatu Perguruan Tinggi terletak di pemeringkatan ini. Misalnya Kopertis 7 yang setiap tahun melakukan pemeringkatan AKU dan setiap tahun pimpinan memerintahkan untuk selalu mengikuti. Jika di tingkat Dikti, komponen tetap disiapkan. Hanya pada tingkat Dikti kan tidak ada pemberitahuan mengenai penilaian, namun begitu saja keluar pemeringkatan.
Untuk tahun ini kami berada di peringkat 78 . Dalam pemeringkatan yang dilakukan oleh Dikti kita kurang tahu apa yang menjadi indikaatornya, mungkin mereka berdasarkan data PDPT ataukah kinerja LPPM serta kinerja pelaporan portal Dikti (Hasil petikan wawancara dengan Bpk UL, tanggal 9 Juli 2018).

Terkait dengan pendapat Bapak UL diatas, selanjutnya peneliti melakukan triangulasi sumber dengan mewawancarai Ibu AM, Dekan FEB UMS dan menanyakan tentang arti penting pemeringkatan bagi UMS. Berikut hasil wawancaranya:

"Ya, pemeringkatan bagi kami itu sangat penting. Artinya hal itu jadi bahan acuan untuk kami meningkatkan kinerja. Biasanya pimpinan akan men-share melalui WA mengenai pemeringkatan PT bahwa posisi PT kita saat ini disini, jadi peringkat di seluruh dunia, di tingkat Indonesia, PTS maupun PTM, bahwa posisi kita sekarang di sini. Kemudian jika ada perubahan atau penurunan sesegera mungkin pimpinan akan menghimbau untuk memperbaiki lagi agar selanjutnya minimal di tingkat Jawa Timur, peringkat kita tidak jauh dari UMM, yang kita tahu panutan kita untuk PTM di Jatim adalah UMM. Alhamdulillah peringkat kita tahun ini lebih baik dari capaian tahun sebelumnya, jadi masih 10 besar di tingkat PTM. (Hasil petikan wawancara dengan Ibu AM, tanggal 17 Juli 2018).

Hasil wawancara dengan Bpk UL dan Ibu AM menyatakan hal yang sama, yakni pemeringkatan memiliki arti penting bagi tiap-tiap universitas. Berdasarkan kedua hasil wawancara tersebut selanjutnya peneliti melakukan triangulasi sumber dengan mewawancarai Ibu HCW, kepala BPM dan ketua tata kelola UMSIDA. Berikut hasil wawancaranya:

"Pemeringkatan perguruan tinggi sangat penting bagi kami karena hal tersebut merupakan indikator seberapa besar kita berkembang dan diterima oleh 
masyarakat dan otomatis hal tersebut merupakan value dalam branding kita. Katakanlah di pemeringkatan AKU KOPERTIS 7, pada saat peringkat kita terus naik berarti menunjukkan bahwa usaha kita selama ini signifikan dengan hasilnya, sebagai indikator bahwa kita sudah mulai berkembang. Jika tidak seperti itu kita akan kesulitan mengukurnya. Karna dari sisi internal saja kita tidak bisa menyimpulkan. Namun jika kita berkompetisi dengan PTS di sekitar kita maka pemeringkatan tersebut bisa menjadi salah satu indikator untuk mengetahui dimanakah posisi kita di sekian banyak PTS. Lalu berikutnya adalah di setiap indikator yang dilakukan oleh Kopertis, BAN-PT, dan lainnya kan mempunyai kriteriakriteria tersendiri. Dari hal tersebut kita bisa membandingkan keadaan kita dengan PT lainnya dan mengetahui dimanakah titik lemah kita. Katakanlah kita lebih unggul di publikasi, namun kita juga mempunyai kelemahan dari sisi kemahasiswaan. Kita menang di tata kelola kelembagaan namun hal tersebut kurang maksimal karena pada waktu itu kita teridentifikasi belum mempunyai sertifikasi selain dari BAN-PT, akhirnya masuklah kita kesertifikasi ISO dan AUN. Kita mengetahui posisi dan titik lemah kita, dan itu membantu progres kita ke depan. Jika kita menginginkan kenaikan maka usaha dan strategi kita selanjutnya adalah seperti ini. Itu nanti akan bersinergi dengan penyusunan strategis yang kita inginkan (Hasil petikan wawancara dengan Ibu HCW, tanggal 17 Juli 2018)

Dengan demikian berdasarkan tiga informan pada tiga perguruan tinggi yang berbeda menyatakan bahwa pemeringkatan perguruan tinggi sangatlah penting, utamanya adalah untuk peningkatan kinerja perguruan tinggi. Pemeringkatan dapat menjadi pemicu dan pemacu semangat seluruh civitas akademik untuk meningkatkan kinerjanya sehingga pemeringkatan ini dapat menjadi ajang bergengsi di antara para pimpinan perguruan tinggi. Hal ini yang dirasakan oleh peneliti pada saat mengikuti banyak kegiatan di berbagai kampus. Misalnya saat rapat dosen Universitas Muhammadiyah Sidoarjo (UMSIDA) tanggal 4 September 2018 (data observasi). Rektor UMSIDA dalam sambutannya menyampaikan berbagai prestasi yang diraih oleh UMSIDA berdasarkan hasil pemeringkatan seperti dari Kopertis Wilayah VII, pemeringkatan dari 4ICU, webometrics, dan pemeringkatan oleh DIKTI. Hal ini menandakan bahwa hasil pemeringkatan sangat penting bagi rektor sebagai wujud dari kinerja yang diraih oleh perguruan tinggi yang dikelolanya. Demikian juga dengan kampus luar negeri, misalnya University of Malaya Malaysia. Pada saat artikel ini ditulis tanggal 22 September 2018, University of Malaya menulis hasil pemeringkatan dunia selama lima tahun berturut-turut pada websitenya (https:// www.um.edu.my/). Hal ini menandakan bahwa baik kampus Indonesia dan kampus luar negeri sangat memperhatikan arti penting dari pemeringkatan yang dapat dijadikan sebagai tolak ukur kinerja dan juga untuk tujuan promosi.

Makna lain dari pemeringkatan sebagai wujud kinerja adalah bahwa hasil pemeringkatan dapat dijadikan sebagai bahan untuk promosi kampus atau dalam rangka meningkatkan dan menjaga image building. Hal ini dapat dilihat di hampir semua website perguruan tinggi yang memperoleh hasil pemeringkatan yang baik. Misalnya sampai saat artikel ini ditulis tanggal 22 September 2018, pada website Universitas PGRI Adibuana Surabaya (http:/ /www.unipasby.ac.id/) masih terpampang tulisan hasil pemeringkatan Kemenristek DIKTI bahwa Universitas PGRI Adi Buana ada di peringkat 78 perguruan tinggi se-Indonesia.

Berdasarkan hasil penelitian yang sudah disampaikan, dapat diketahui proses penelitiaan yang dilakukan, yakni dengan menggabungkan antara teknik pengumpulan data in depth interview, observasi, dokumentasi, dan observasi. Proses in depth interview sekaligus sebagai proses uji triangulasi sumber, yakni hasil wawancara dengan informan Bapak UL dikonfirmasi kepada Ibu AM, dan Ibu HCW. Proses uji triangulasi metode juga dilaksanakan dengan cross check antara in depth interview dengan observasi, dokumentasi, dan observasi. Berikut gambaran uji triangulasi dalam penelitian ini.

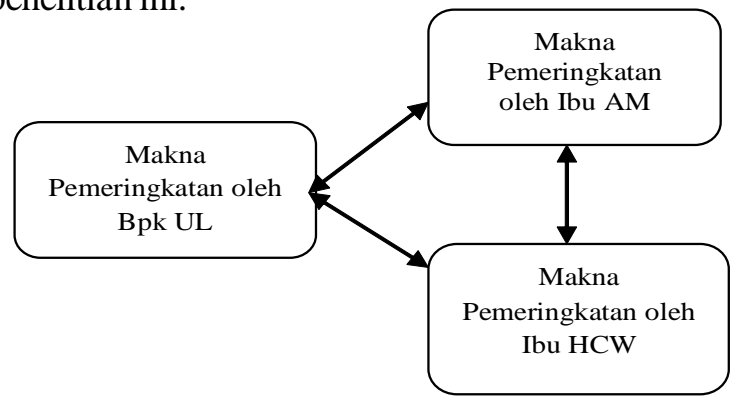

Gambar 1. Proses Triangulasi Sumber Atas Makna Pemeringkatan

Sumber: Hermawan dan Amirullah, 2016 


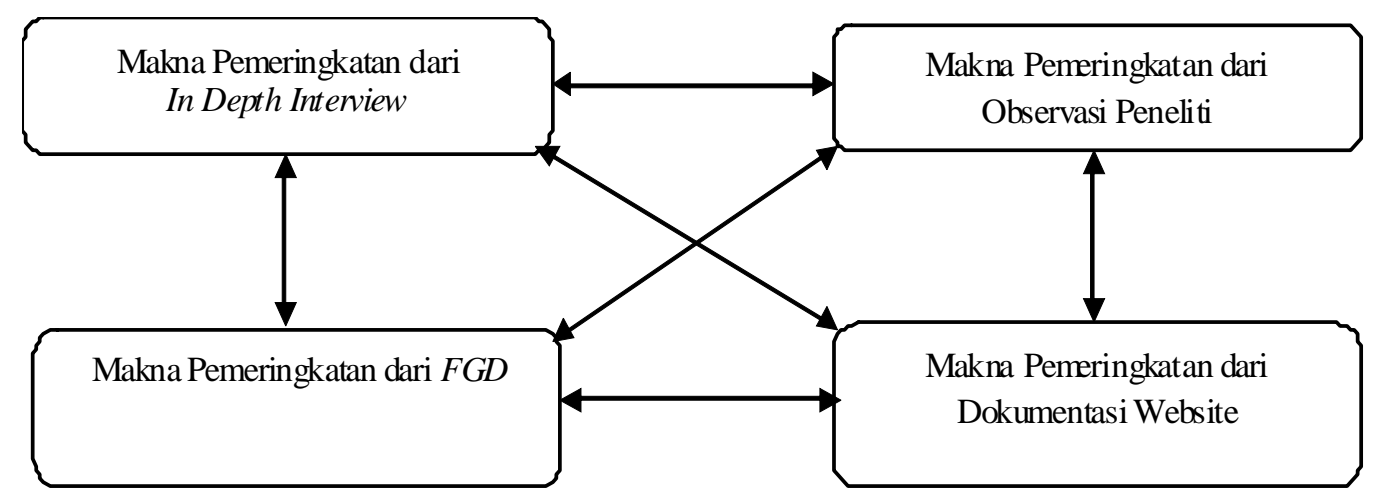

Gambar 2. Proses Triangulasi Metode Atas Makna Pemeringkatan

Sumber: Hermawan dan Amirullah, 2016

Untuk dapat sampai pada hasil penelitian kinerja dan daya saing perguruan tinggi Indonesia perspektif intellectual capital, peneliti melakukan teknik pengumpulan data dengan in depth interview, FGD, dan dokumentasi. Pada saat proses pengumpulan data tersebut juga dilakukan keabsahan data dengan uji triangulasi sumber dan metode, proses data reduction dan coding sehingga didapatkan tema atau konsep yang sama (lihat Tabel 5). Pada tahapan tersebut juga dilakukan triangulasi teori dengan teori dasar, yakni the resources based theory.

Sebagaimana telah dijelaskan sebelumnya bahwa makna pemeringkatan adalah terkait dengan cerminan kinerja perguruan tinggi maka berbagai upaya dilakukan agar kinerja perguruan tinggi tersebut meningkat sehingga daya saing juga meningkat. Caranya adalah dengan memperhatikan hasil pemeringkatan dan mengambil langkah-langkah strategis agar peringkat perguruan tinggi meningkat. Hal ini seperti disampaikan oleh Bapak UL, wakil rektor II Universitas Adi Buana Surabaya berikut ini :

"Disini ada UPT IT yang bertanggung jawab untuk hal tersebut. Secara teknis UPT IT membuat webnya, dan materi didapat dari unitunit. Misalnya Penjaminan Mutu ingin memberikan informasi maka data dimasukkan melalui UPT IT. UPT IT disini langsung di bawah naungan rektorat, tidak di bawah wakil rektor karena nantinya kan menyangkut akademik, tata kelola serta kemahasiswaan. Sistem Informasi kami disebut MITRA, Manajemen Informasi Terintegrasi. Ada MITRA Akademik, MITRA Keuangan juga MITRA Kemahasiswaan. Keuangan kita dengan eksternal menyangkut pembayaran keuangan mahasiswa secara online dan sinkron dengan akademik. Namun juga ada perlakuan khusus bagi mahasiswa tertentu terkait presensi. Kalau MITRA Kemahasiswaan berisi tentang kegiatan aktivitas mahasiswa yang kaitannya dengan poin yang didapat oleh mereka yang menjadi prasyarat 75 poin minimal untuk mengikuti yudisium. Setiap mahasiswa mengikuti kegiatan dia bisa entry secara online, nantinya diverifikasi oleh Kemahasiswaan sehingga akhirnya hanya tinggal mencetak secara kumulatif total yang poin yang didapatkan. Selain itu kita juga punya SIMPEG, BMP dan LP2M. Website ini kepentingan internal namun bisa diakses oleh eksternal dimana saja. Misalnya dosen yang ingin melakukan entry nilai dia bisa melakukan via MITRA Akademik dimana saja dia berada" (Hasil petikan wawancara dengan Bpk UL, tanggal 9 Juli 2018).

Maksud dari pernyataan Bapak UL adalah bahwa upaya untuk menaikkan peringkat UNIPA Surabaya adalah dengan penanganan Information Technology (IT). Caranya melalui UPT IT yang memang secara teknis membuat dan maintenance website serta bertanggung jawab terhadap berbagai program sistem informasi kampus. Website universitas memang menjadi menjadi tolok ukur pemeringkatan khususnya pemeringkatan webometrics. Dengan cara yang demikian diharapkan kinerja perguruan tinggi dapat diketahui oleh khalayak ramai dan meningkatkan akses website sehingga meningkat pula hasil pemeringkatan.

Berdasarkan hasil wawancara dengan Bapak UL ini selanjutnya peneliti melakukan triangulasi sumber dengan mewawancarai Ibu AM tentang langkah yang dilakukan oleh UM Surabaya dalam meningkatkan kinerja pemeringkatan ini. Berikut komentarnya :

"Kita masih bersifat top-down untuk hal tersebut. Jadi biasanya Rektor memberikan arahan misalnya "Oh publikasi ini harus ditambah lagi," 
nah itu nanti kebijakannya Warek I" (Hasil petikan wawancara dengan Ibu AM, tangga l17 Juli 2018)

Disinggung tentang upaya meningkatkan pemeringakatan perguruan tinggi melalui website berikut komentar ibu AM :

"Untuk pengembangan sistem informasi kita ada semacam UPT untuk menanganinya. Ada web Perguruan Tinggi secara umum, ada juga web dari masing-masing fakultas. Dari masing-masing fakultas mendelegasikan perwakilannya untuk dilatih oleh UPT tersebut dan selanjutnya merekalah yang bertanggung jawab untuk mengontrol web dari masing-masing fakultasnya. Karena sebelum Perguruan Tinggi kami melakukan sentralisasi ternyata beberapa unit bagian sudah mempunyai website terlebih dahulu, jadi mereka sudah mengelolanya dahulu dan yang lain belum. Akhirnya disentralisasi agar sama outputnya, istilahnya layout diseragamkan". (Hasil petikan wawancara dengan Ibu AM, tanggal 17 Juli 2018)

Berdasarkan hasil wawancara dengan Bapak UL dan Ibu AM selanjutnya peneliti melakukan triangulasi sumber dengan mewawancarai Ibu HCW yang tentang respon pimpinan UMSIDA atas hasil pemeringkatan dan upaya menaikkan pemeringkatan melalui website. Berikut komentarnya :

"Saat kita mengetahui bahwa terdapat universitas baru (Universitas PGRI Madiun yang sebelumnya berstatus STKIP PGRI Madiun) yang masuk dalam 5 besar peringkat, kita seperti kebakaran jenggot. Akhirnya kita mencari tahu kenapa STKIP tersebut sampai bisa naik. Hal tersebut yang menjadi fokus pimpinan, yang tentunya akan di-breakdown ke kita sebagai pelaksana untuk mencari branchmarking mengenai strategi STKIP untuk naik. Yang dari branchmarking tersebut kita tahu bahwa ternyata strategi STKIP untuk naik adalah seperti ini. Nah strategi ini yang coba kita sampaikan ke pimpinan untuk selanjutnya diadopsi" (Hasil petikan wawancara dengan Ibu HCW, tanggal 17 Juli 2018).

Terkait dengan upaya meningkatkan kinerja pemeringkatan melalui website, berikut komentarnya :

"Webometrik ini kan terkait dengan pemanfaatan web, kita mengarah pada program e-learning.
Kita pernah melakukan studi banding dengan Universitas Narotama, mengapa mereka sangat tinggi untuk webometriknya. Ternyata mereka menggunakan e-learning, itu yang kita adopsi. Lalu dibentuklah penyusunan program e-learning itu di UMSIDA" (Hasil petikan wawancara dengan Ibu HCW, tanggal 17 Juli 2018).

Berdasarkan hasil wawancara dengan tersebut dapat diketahui bahwa perguruan tinggi berupaya untuk meningkatkan kinerja pemeringkatannya melalui wesbsite dan sistem informasi yang digunakan untuk operasional akademik dan non akademik.

Sementara itu berkaitan dengan kinerja dan daya saing perguruan tinggi, pemeringkatan yang diperoleh pergurun tinggi adalah hasil dari kinerja semua pihak yang ada di perguruan tinggi. Artinya hasil pemeringkatan oleh webometrics, 4ICU, dan DIKTI adalah cerminan kinerja perguruan tinggi. Maksudnya adalah pimpinan perguruan tinggi tetap harus meningkatkan kinerjanya agar peringkatnya meningkat. Peningkatan kinerja dan daya saing dapat dilakukan berdasarkan perspektif intellectual capital, yang terdiri dari human capital, structural capital, dan relational capital. Tentang pentingnya intellectual capital dalam meningkatkan kinerja perguruan tinggi juga dibahas pada saat in depth interview dan $F G D$. Terkait dengan hubungan financial capital $(F C)$ dan human capital $(H C)$ dalam meningkatkan kinerja perguruan tinggi berikut komentar Ibu IDR, Kepala BAK UMSIDA:

"Kita agak sedikit terlambat dalam berbenah jika kita berbicara IC atau HC. Dari data BPSDM, prosentase Dosen S3 masih sangat kecil, apalagi jika kita lihat pada Guru Besar hanya $1 \%$ dari jumlah Dosen Tetap yang ada. Prioritas yang dibangun oleh UMSIDA saat ini memang banyak ke arah SDM atau HC. Berdasarkan money follow function, jika $\mathrm{HC}$ meningkat pastikan FC juga mengikuti. Dari RAB kemarin juga sudah ada target KPI yang harus dipenuhi oleh masingmasing unit terkait dengan $\mathrm{HC}$, kalau FC tentunya akan menyesuaikan dengan prioritas yang dibangun. Harapannya bisa meningkatkan kinerja Umsida" (Hasil petikan wawancara dengan Ibu IDR, saat FGD tanggal 20 Juli 2018).

Pendapat yang sama disampaikan oleh Ibu HCW tentang $H C$ di UMSIDA, berikut komentarnya:

"Program renstra yang kita jalankan melalui BPSDM adalah memberikan bantuan studi lanjut 
S3 untuk tenaga pendidik, kualifikasi pendidikan, kualifikasi jabatan akademiknya. Lalu UMSIDA menggenjot di pelatihan tenaga kependidikan dan dosen misalnya pelatihan publikasi. Namun satu hal yang akan dilakukan adalah peningkatan kemampuan bahasa inggris/toefl bagi tenaga kependidikan/karyawan dan dosen. Hal ini adalah salah satu persiapan untuk program internasionalisasi institusi". (Hasil petikan wawancara dengan Ibu HCW, tanggal 17 Juli 2018).

Tentang pentingnya $H C$ dalam meningkatkan kinerja perguruan tinggi juga disampaikan oleh Bapak REF, dosen dan tenaga ahli MSDM. Berikut komentarnya:

"Saya lebih menyoroti pada HC karena yang saya ketahui jika berhubungan dengan kinerja dan daya saing maka yang lebih dulu diperkuat oleh suatu organisasi adalah SDM terlebih dahulu. Jadi kalau SDM sudah kuat, meskipun tanpa dibekali oleh structural capital (SC) yang baik, akan tetap bisa memiliki daya saing yang tinggi. Jika $S C$ sudah ditingkatkan maka akan menghasilkan kinerja dan daya saing yang lebih tinggi lagi”. (Hasil petikan wawancara dengan Bapak REF, saat FGD tanggal 20 Juli 2018).

Selain HC, komponen intellectual capital lainnya adalah structural capital (SC) seperti teknologi informasi, budaya organisasi, perangkat keras dan perangkat lunak. Tentang pentingnya $S C$ dalam meningkatkan kinerja perguruan tinggi disampaikan oleh Bapak AR, berikut komentarnya:

"Menurut saya untuk mencapai kinerja dan daya saing sebenarnya SC yang perlu dibangun dan dikuatkan. Karena tanpa SC maka kita akan kalah dengan PT lain yang telah terbangun dan tersistem SC-nya. Jika kita berbicara tentang teknologi, mengapa orang cenderung membangun SC yang simple dengan adanya teknologi. Tapi sebenarnya itu keliru, jika kita berbicara PT maka struktur itu harus dibangun secara komprehensif. Misalnya di UMSIDA, $S C$ yang terbangun masihlah sangat jauh jika dibandingkan dengan PT lain, nah ini yang perlu dikuatkan secara komprehensif”. (Hasil petikan wawancara dengan Bapak AR, saat FGD tanggal 20 Juli 2018).

Berikutnya selain $H C$ dan $S C$, ada relational capital $(R C)$ yang perlu dibangun untuk meningkatkan kinerja perguruan tinggi. $R C$ yang dimiliki berupa kerjasama dengan berbagai pihak termasuk dengan luar negeri, pemanfaatan HAKI dan hubungan dengan masyarakat lainnya. Untuk pentingnya hal ini disampaikan oleh Ibu HF berikut ini:

"Jadi kalau menurut Saya yang penting adalah jejaring atau $R C$. Kita lihat PT di Jatim misalnya Universitas Ciputra (UC) dan UII Jogjakarta. Mereka itu selalu mengembangkan jejaring atau relational capital. Misalnya UC itu mengembangkan jejaring dengan Dinas Perindustrian Sidoarjo. Mereka menawarkan konsep entrepreneur pada Dinas tersebut. Program tersebut adalah menggali data, artinya mereka juga menjadi masukan mahasiswanya. Jika mahasiswa ingin menjadi seorang entrepreneur yang bagus dan berhasil maka terjunlah ke entrepreneur yang benar-benar menjalankan usaha. Akhirnya mahasiswa masuk ke UKM di Sidoarjo, dan UKM tidak merasa terbebani oleh mereka karena saling diuntungkan. Dinas Perindustrian Sidoarjo mendapatkan data industri olahan makanan yang didapat dari program mahasiswa Ciputra. Jadinya ada jejaring atau $R C$ dari pemerintah dengan pihak kampus, dan tidak hanya berhenti di fakultas namun sampai pada mahasiswa. Ini pentingnya $R C$ dalam meningkatkan kinerja perguruan tinggi". (Hasil petikan wawancara dengan Ibu HF, saat FGD tanggal 20 Juli 2018).

Hal yang sama disampaikan oleh Ibu SMT, yang menyatakan bahwa $R C$ penting dalam meningkatkan kinerja perguruan tinggi. Berikut komentarnya:

"Menurut saya yang paling signifikan adalah $R C$, karena daya saing PT saat ini berdasarkan apa yang dibutuhkan oleh dunia usaha. Jadi semua kompetensi, semua yang dimiliki oleh PT outputnya adalah semua yang diinginkan oleh dunia usaha. Jadi bagaimana PT itu bersinergi atau juga berkolaborasi dengan dunia usaha, maka harus punya modal relasi $(R C)$ yang bagus dengan semua pihak". (Hasil petikan wawancara dengan Ibu SMT, saat FGD tanggal 20 Juli 2018).

Hal yang berbeda disampaikan oleh Ibu SB, yang menyatakan bahwa semua komponen IC itu semua penting dan semua saling mempengaruhi kinerja perguruan tinggi. Berikut komentarnya:

"Antara $H C, S C$ dan $R C$ saling berhubungan. Saya ambil contoh di Universitas Ciputra Surabaya, ketiga komponen $I C$, yakni $H C, S C$, 
dan $R C$-nya sangat kuat. Jadi $H C, S C$ dan $R C$ saling berhubungan dan kita tidak bisa menentukan mana yang paling menonjol dari ketiga aspek tersebut karena dengan kurangnya salah satu dari ketiga faktor tersebut maka akan sangat mempengaruhi daya saing suatu PT". (Hasil petikan wawancara dengan Ibu SB, saat FGD tanggal 20 Juli 2018).

Terkait dengan peningkatan kinerja dan daya saing perguruan tinggi, peneliti menawarkan konsep Comprehensive Intellectual Capital Management (CICM) pada informan Ibu HCW. Menurut beliau saat ini UMSIDA ada di tahapan innovation management dari tiga tahapan yang ada. Berikut komentarnya:

"Menurut Saya untuk tahapan pertama, yakni knowledge managemet, UMSIDA sudah melewatinya. Dasar pembelajaran seperti pelatihan Pekerti, penyusunan RPS, meskipun sekian persen dosen masih outlayer. Sekarang ini UMSIDA dalam tahapan innovation management. Ada beberapa tujuan yang sudah mengarah kesana, misalnya salah satu bentuk inovasi kita, sebut saja e-learning itu meskipun sudah biasa di luar namun itu kan merupakan suatu inovasi dari kita sebenarnya. Lalu pemanfaatan sistem informasi dengan pola terintegrasi (mycampus.umsida.ac.id), ini merupakan salah satu inovasi di Umsida. Inovasi lainnya adalah lebih banyak dosen kita yang mulai berani tampil di kegiatan ilmiah di luar, baik Nasional maupun Internasional". (Hasil petikan wawancara dengan Ibu HCW, tanggal $17 \mathrm{Juli}$ 2018).

Berdasarkan hasil wawancara yang telah dipaparkan tentang kinerja dan daya saing perguruan tinggi Indonesia dapat diketahui beberapa hal, yakni pemeringkatan perguruan tinggi oleh lembaga pemeringkat sangat mempengaruhi respon atau tindakan yang dilakukan oleh pimpinan perguruan tinggi. Berikutnya adalah upaya untuk menaikkan peringkat perguruan tinggi adalah dengan penguatan dan maintainance website kampus dan juga mengembangkan sistem informasi baik sistem akademik dan non akademik. Sementara itu untuk meningkatkan kinerja perguruan tinggi dapat dilakukan dengan optimalisasi peran intellectual capital baik secara individual $H C, S C$, dan $R C$ ataupun juga $I C$ sebagai satu kesatuan utuh yang terintegrasi. Adapun metode yang dapat dipakai untuk meningkatkan kinerja perguruan tinggi berbasis intellectual capital adalah Comprehensive Intellectual Capital Managemet (CICM).

Makna pemeringkatan dan upaya meningkatkan kinerja dan daya saing perguruan tinggi berbasis intellectual capital dapat dianalisis dengan dua teori dasar, yakni teori referensial dan teori sumber daya atau the resource based theory (Wernerfelt, 1984; Barney, 1991). Teori referensial digunakan untuk makna pemeringkatan dan the resources based theory untuk upaya meningkatkan kinerja dan daya saing perguruan tinggi. Teori referensial adalah salah satu dari sekian banyak teori makna. Atau juga bahwa teori referensial merupakan salah satu jenis teori makna yang mengenali atau mengidentifikasi makna suatu ungkapan dengan apa yang diacunya atau dengan hubungan acuan itu. Sementara itu teori sumber daya atau the resources based theory adalah teori yang mengungkapkan tentang pentingnya sebuah organisasi atau lembaga memanfaatkan sumber daya yang dimilikinya baik yang bersifat tangible dan intangible.

Terkait dengan hasil penelitian ini tentang makna pemeringkatan dikaitkan dengan teori referensial mengandung makna bahwa pemeringkatan ini penting sebagai tolak ukur kinerja dan juga sebagai media promosi yang akan disampaikan pada berbagai media kampus apabila peringkatnya meningkat. Makna lain bahwa pemeringkatan perguruan tinggi juga mengandung makna prestise seorang rektor atau pimpinan perguruan tinggi atas prestasi kampusnya. Apabila dikaitkan dengan teori referensial maka pimpinan perguruan tinggi akan mengacu pada hasil pemeringkatan tersebut untuk mengembangkan berbagai strategi dan program kerja untuk mengembangkan kampusnya. Atau dengan bahasa lain bahwa makna pemeringkatan ini seperti halnya "memberi cermin" pada pimpinan perguruan tinggi atas berbagai upaya dan kegiatan yang telah dilakukan selama ini.

Sementara itu, tentang the resourse based theory yang dikaitkan dengan hasil penelitian ini maka akan berhubungan dengan upaya yang dilakukan perguruan tinggi untuk meningkatkan kinerja dan daya saing. Secara teknis yang dilakukan oleh perguruan tinggi adalah membenahi maintenance website dan sistem informasi yang digunakan baik untuk akademik dan non akademik, termasuk juga mengembangkan e-learning untuk proses pembelajaran. Perspektif lain yang dapat digunakan terkait dengan the resource 
based theory adalah mengembangkan komponen intellectual capital yang dimiliki oleh perguruan tinggi. Komponen tersebut adalah human capital, structural capital, dan relational capital. Menurut informan penelitian bahwa semua komponen tersebut ( $H C, S C$, dan $R C$ ) penting dan dapat meningatkan kinerja dan daya saing perguruan tinggi baik dilakukan secara individual ataupun secara terintegrasi sebagai $I C$.

Hasil penelitian ini mendukung penelitian yang dilakukan oleh Anggraini et al (2018) yang menyatakan bahwa ada hubungan yang signifikan antara IC dengan elemen-elemen kinerja universitas. Selanjutnya penelitian ini juga memberikan rekomendasi pada universitas untuk melakukan investasi pada human capital, structural capital, dan relational capital. IC juga dinyatakan sebagai model baru pengukuran untuk kinerja univesitas yang menyediakan nilai tambah bagi penguatan kemampuan bersaing.

Hal seperti ini mendukung penelitian Hermawan (2015). Metode lain dalam perspektif IC yang dapat digunakan untuk meningkatkan kinerja dan daya saing perguruan tinggi adalah dengan comprehensive intellectual capital management atau CICM (AlAli, 2003). Hasil penelitian Hermawan (2015) menyatakan bahwa metode CICM terbukti dapat meningkatkan kinerja dan daya saing perusahaan farmasi Indonesia. Demikian pula dengan perguruan tinggi di Indonesia dapat juga menggunakan metode CICM untuk meningkatkan kinerja dan daya saingnya. Namun hal yang perlu diperhatikan adalah perguruan tinggi harus dapat mengidentifikasi posisinya di tahapan $C I C M$. Adapun $C I C M$ mempunyai tiga tahapan, yakni knowledge management, innovation management, dan intellectual property management. Dengan mengetahui posisi perguruan tinggi pada tahapan CICM akan mempermudah untuk mencari formula dalam pengembangan perguruan tinggi.

\section{SIMPULAN}

Kesimpulan penelitian ini adalah makna pemeringkatan bagi perguruan tinggi adalah sangat penting karena terkait dengan kinerja, media promosi, dan juga reputasi atau image building. Sementara itu upaya untuk meningkatkan kinerja dan daya saing perguruan tinggi dapat dilakukan dengan mengembangkan dan maintenance website dan sistem informasi yang dimiliki perguruan tinggi. Selain itu peningkatan kinerja dan daya saing dapat juga dengan perspektif intellectual capital yang terdiri dari tiga komponen, yakni human capital, structural capital, dan relational capital. Cara lain untuk meningkatkan kinerja dan daya saing perguruan tinggi dalam perspektif $I C$ adalah dengan metode comprehensive intellectual capital management atau CICM.

Saran penelitian ini adalah pemeringkatan perguruan tinggi oleh lembaga dalam dan luar negeri memberikan makna penting bagi pimpinan perguruan tinggi. Dengan demikian pimpinan perguruan tinggi dan segenap civitas akademika harus meningkatkan kinerjanya agar hasil pemeringkatan bisa tinggi. Caranya dapat menggunakan intellectual capital ( $H C, S C$, dan $R C$ ) dan dapat juga dengan metode CICM.

\section{Informasi Tambahan}

Ucapan terima kasih disampaikan kepada DP2M Kemenristek DIKTI yang sudah membiayai penelitian ini. Artikel ini adalah hasil dari Penelitian Terapan Unggulan Perguruan Tinggi (PTUPT) Tahun 2018.

\section{REFERENSI}

Al-Ali, N. (2003). Comprehensive Intellectual Capital Management. John Wiley \& Sons, Inc., Hoboken, New Jersey.

Anggraini, Fivi., Mohamad Ali Abdul-Hamid., M. K. A. A. (2018). The Role of Intellectual Capital on Public Universities Performance in Indonesia. Pertanika Journal Social Science And Humanities, Vol 26(No 4), 2453 - 2472.

Barbosa, Soraia., Jose Vale., Vera Teixiera Vale., M. C. B. (2016). Intellectual Capital and Performance in Higher Education Organizations. Theory And Applications In The Knowledge Economy, PP/ : 670-681.

Basuki. (2011). Metodologi Studi Kasus, Desain Penelitian. Modul. Pelatihan Metodologi Riset. 6 - 7 Desember. Departemen Ekonomi Syariah. FEB Unair Surabaya.

Belkaoui, A. R. (2003). "Intellectual Capital and Firm Performance US Firm. A Study of The Resource Based and Stakeholders View." Journal of Intellectual Capital, Vol 4(No 2), pp 215-226.

Bontis, N., and William, C. C. K., and Stanley, R. (2000). Intellectual Capital and Business Performance in Malaysian Industries. Journal of Intellectual Capital, Volume 1(No 1), 85-100. 
Hayat, Aamir., Muhammad Azeem., Adiba Latif., and Asad Afzal Humayon. 2019. Analyzing The Moderating Role of Knowledge Management In The Relationship Between Intellectual Capital And Organizational Performance. International Journal of Economics, Commerce and Management. Vol VII Issue 4, pp 409-433.

Hermawan, Sigit., dan Lia Debby Milanetty. 2018. The Comparison of Intellectual Capital Disclosure: Evidence from Pharmaceutical Company in Southest Asian Countries. Advances in Social Science, Education and Humanities Research (ASSEHR), volume 125, pp 45-49.

Hermawan, Sigit., Wiwit Hariyanto., Herman Ernandi., Sri Iswati, dan Z. F. (2012). Model Pengelolaan dan Pengembangan Intellectual Capital Guna Meningkatkan Kinerja Bisnis Industri Farmasi dan Meraih Keunggulan Bersaing Tingkat Global. Laporan Penelitian Hibah Pekerti DP2M DIKTI Kemendikbud.

Hermawan, Sigit., dan S. H. (2013). Studi Interpretif Identifikasi dan Interaksi Intellectual Capital Terhadap Kinerja Perusahaan. Jurnal Reviu Akuntansi Dan Keuangan FEB Akuntansi Universitas Muhammadiyah Malang, 3(1), 335-347.

Hermawan, S. (2013). Makna Intellectual Capital Perspektif The Role Theory dan The Resource Based Theory. Ekuitas/ : Jurnal Akuntansi Dan Keuangan, Vol. 17(No. 2), Pp. 275.

Hermawan, S. (2015). Intellectual Capital Empowerment Through Comprehensive Intelelctual Capital Management. Proceeding. The 1st International of Joint Conference of Indonesia-Malaysia-Bangladesh-Ireland. 27-28 April. Banda Aceh.

Hermawan, S., \& Amirullah. (2016). Metode Penelitian Bisnis Pendekatan Kuantitatif dan Kualitatif. Malang: Penerbit MNC.
Http://kelembagaan.ristekdikti.go.id

Https://www.um.edu.my/

Http://www.unipasby.ac.id/

Http://www.webometrics.info/en/Asia\%0A\%0A

J Barney. (1991). Firm Resources and Sustained Competitive Advantage. Journal of Management, (17), 99-120.

Khalique, M., J. A. N. Shaari., A. B. M. Isa, dan A. A. (2011). Role of Intellectual Capital on the Organizational Performance of Electrical SMEs in Pakistan. International Journal of Business and Management, 6(9), 253-257.

Miles, M. B., dan A. M. H. (1984). Qualitative Data Analysis. Sage Publication Inc. USA.

Popescu, Cristina Raluca GH. 2019. "Intellectual Capital": Major Role, Key Importance and Decisive Influences on Organizations' Performance. Journal of Human Resources Management Research. Vol. 2019. pp. 1-17

Senton, A. K. (2004). Strategies for Ensuring Trustworthiness in Qualitative Research Project. Education for Information, 22, 63-75.

Sharabati, A. A. A., S. N. Jawad, dan N. B. (2010). Intellectual Capital and Business Performance in the Pharmaceutical Sector of Jordan. Management Decision, 48(1), 105-131.

Strauss, A., dan J. C. (2003). Dasar-Dasar Penelitian Kualitatif. Yogyakarta: Penerbit Pustaka Pelajar.

Sriwahyuni, Diana., Sigit Hermawan., dan Nur Ravita Hanun. 2019. Intellectual Capital Terhadap Kinerja Keuangan Perusahaan Farmasi Indonesia. EBA Journal. Vol 5 No 1, hlm 31-38. Syaifudin, A. (2016). Mengalibrasi Peringkat Universitas. Retrieved from http://republika. co.id/berita/ koran/opini-koran/16/08/19/ oc5cw214-mengalibrasi-peringkat-universitas.

Wernerfelt, B. (1984). A Resource Based View of the Firm. Strategic Management Journal, 5(5), 171-180. 